\title{
INVESTIGATION OF ECO-FRIENDLY CELLULOSIC NANOPARTICLES POTENTIAL AS REINFORCEMENT AGENT IN THE PRODUCTION OF NATURAL RUBBER COMPOSITES
}

\author{
J. O. Oboh ${ }^{1,}$, J.O. Okafor ${ }^{2}$, A. S. Kovo ${ }^{3}$ and A. S. Abdulrahman ${ }^{4}$

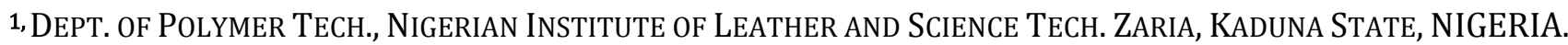

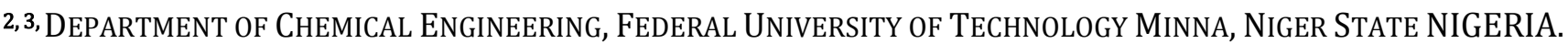 \\ 4, Dept. of Material and MetalluRgical Engr. Fed. University of TeChnology, Minna, Niger State, NiGERIA \\ E-mail addresses:1 labconsult@yahoo.com, ${ }^{2}$ jookai2003@yahoo.com, ${ }^{3}$ kovoabdulsalami@gmail.com, \\ 4 aspita.salawu@futminna.edu.ng
}

\begin{abstract}
This research focuses on the use of cellulosic nanoparticles obtained from coconut husk, bamboo and cotton linter as reinforcing phase in natural rubber composites with the objective to study the effect of these cellulosic particles and loading ratio on the mechanical, thermal and morphological properties of the resultant composites. Vulcanized natural rubber composites were prepared using cellulosic nanoparticles obtained from bamboo (BNC), coconut husk (CHNC), cotton linter (CLNC) and carbon black (CB) as reinforcing material/fillers. These reinforcing material/fillers were compounded alongside with vulcanizing agents using two roll mixing mill and subsequently cured in order to introduce crosslinks into rubber chains. Scanning electron microscope (SEM) revealed that the free volume holes in the neat rubber were drastically reduced by incorporation of these nanoparticles into the rubber matrix. The differential scanning calorimetric (DSC) study showed a slight shift in the melting temperature of bamboo based composite from 360 to $350^{\circ} \mathrm{C}$ while thermo gravimetric analysis (TGA) showed that the incorporation of bamboo and cotton linter based nanoparticles shifted the thermal stability of neat rubber matrix from 266 to 299 and $300{ }^{\circ} \mathrm{C}$ respectively. Coconut husk based composites showed a trend of increase in tensile strength from 1.8 to $3.82 \mathrm{MPa}$ with filler loading of 0 to 25 weight \%, while bamboo, cotton linter and carbon black based nanocomposites gave their highest values of 3.16, 3.92 and 4.50 MPa respectively at filler content of 30 weight \%.Cellulosic nanoparticles obtained from biomass studied in this experiment can replace or serve as alternative materials to carbon black especially in moderate load bearing rubber articles
\end{abstract}

Keywords. Mechanical Properties; Cellulosic Nanoparticles; Rubber-Matrix Composites; Carbon Black.

\section{INTRODUCTION}

In recent times, polymers reinforced with cellulosic nanofibre/nanoparticles have attracted tremendous interest because of their eco-friendliness [1] as well as enhanced mechanical and biodegradation properties due to the nanometric size of the cellulose matrix. The biodegradability, high mechanical properties, low density and availability from renewable resources and diversity of the sources of cellulose have presented them as a competing candidate for polymer reinforcement [1]. Natural rubber (NR) is a green biopolymer with high molecular weight of isoprene (2methyl 1, 3 butadiene) and it is obtained from agricultural source. NR in its raw and uncured state possesses low strength, highly dimensionally unstable under thermal and loading conditions and practically has no use [2]. Hence raw rubber is usually reinforced and vulcanized in order to meet useful application conditions. Sulphur or peroxide vulcanization is a chemical process that inserts three dimensional network structures into the polyisoprene polymeric chains and transforms the initially soft-weak plastic material into a strong elastic product with high and reversible deformation and good mechanical properties owing to its strain induced crystallization [3-4]. The inherent strength of vulcanized natural rubber can be further improved upon by interfacing the rubber with a reinforcing phase such as carbon black 
and silica particles in order to obtain improved modulus and durability required for structural and engineering applications. The use of silica filler is expensive while carbon black has been reported to be carcinogenic and limits the aesthetic design of rubber products [5]. The essential attributes of a reinforcing phase has been reported to be particle size (high surface area), strength and strong interfacial interaction between polymer matrix and reinforcing materials. The function of the reinforcing phase is basically to transfer the applied stress from the rubber matrix to the strong and stiff reinforcing materials [6] Rubber matrix reinforced with nanoparticles have been reported to a lesser extent when compared to plastic (thermoplastic and thermoset) matrix [7] with most of the works focusing on the use of carbon nanotubes and nanosilicates as reinforcing phase [8]. The use of different processing methods such as melt intercalation, solution casting, latex blending, two roll mixing mill etc. has been reported [8-9].Two roll mixing mill has the potential to be adapted for commercial use [10]. This research focuses on the use of cellulosic nanoparticles obtained from coconut husk, bamboo and cotton linter via "alkaline-peroxide treatment, mechanical grinding and ball milling" as reinforcing phase in natural rubber composites with the objective to study the effect of these cellulosic particles and loading ratio on the mechanical, thermal and morphological properties of the resultant composites. Despite the readily availability of these biomass in Nigeria, coconut husk has no industrial use presently in Nigeria and are usually thrown away as waste thereby contributing to the menace of municipal solid waste in areas where they are cultivated, similarly bamboo, a wild weed in the rain forest region of Nigeria is under-utilized by the construction industries while cotton farmers predominantly in Northern Nigeria are rendered redundant as a result of the collapse of the Nigeria textile industry. In this experiment, natural rubber will be compounded with nanoparticles obtained from the aforementioned biomass using two roll mixing mill and will be compared with that compounded with a commercial grade N330 carbon black under the same condition in order to assess their extent of reinforcement.

\section{MATERIALS AND METHODS}

\subsection{Materials}

Dry natural rubber crumb, carbon black, stearic acid, mercaptobenzothiazoledisulfide

(MBTS), trimethylquinolone (TMQ), and zinc oxide were supplied by Tony West rubber factory, Lagos Nigeria. The specifications of the dry rubber according to the supplier were $\leq 0.05 \%$ dirt content, $\leq 1.00 \%$ volatile content, $\leq 0.7 \%$ nitrogen content, $\leq 0.6 \%$ ash content, minimum of 30 initial plasticity, minimum of 60 plasticity retention index (PRI)and blackish brown in colour. The carbon black was of N330 grade and was manufactured by Warri refinery and petrochemical a subsidiary of Nigerian National Petroleum Corporation (NNPC) with particle size distribution of 50 to $500 \mathrm{~nm}$. Other compounding ingredients were of rubber processing commercial grade and were used as received. The cellulosic nanoparticles obtained from treated biomass through mechanical process were used as reinforcing filler (nanoreinforcement phase) and they were of particle size distributions of 32 - 175, 68 311 and 620 to $5408 \mathrm{~nm}$ for bamboo, coconut husk and cotton linter sources respectively.

\subsection{Methods}

\subsubsection{Preparation of Cellulosic Nanoparticles}

The top-down method of producing nanoproduct which involves the disintegration of macroscopic material to nano-scale through mechanical grinding and friction shearing was employed. Coconut husk and bamboo were defibered by mechanical beating and retting process. The fibres of the various biomass were further treated using mixture of $1.5 \% \mathrm{H}_{2} \mathrm{O}_{2} / 2 \% \mathrm{NaOH}$ solution at $75 \pm 5{ }^{\circ} \mathrm{C}$ for $4 \mathrm{~h}$ at solution to fibre ratio of $20: 1$ on weight basis. The fibre/solution mixture was left for another $48 \mathrm{~h}$ at ambient temperature and finally, they were washed, rinsed with distilled water to a neutral $\mathrm{pH}$ and sundried. The dried bamboo, coconut husk and cotton lint fibres were chopped manually with the aid of a pair of scissor to an average length of less than $10 \mathrm{~mm}$. the chopped fibres were further milled repeatedly in a Thomas-Wiley laboratory mill through $0.05 \mathrm{~mm}$ mesh sieve. The ground particles recovered from this process was further screened through a 125 $\mu \mathrm{m}$ (sieve mesh number 120 according to BS410) sieve mesh. The milled micro-particles recovered from the above process were ball milled at an estimated vessel speed of $300 \mathrm{rpm}$ at ball to particle ratio (BTP) of 1: 20 on weight basis with an average porcelain ball diameter of $2 \mathrm{~cm}$ for $30 \mathrm{~h}$ each. The particles were subjected to particle size distribution measurement with the aid of Malvern mastersizer 3000 (Malvern instrument UK). This equipment uses the principle of light scattering to measure the diffusion of particles under Brownian motion.

\subsubsection{Compounding of Composites}

Composites of nanoparticles (coconut husk, bamboo, cotton linter and carbon black) and natural rubber as the matrix were prepared using a two roll mill in 
accordance with ASTM D3184-80 method, followed by in-situ moulding and curing. The mixing/compounding of the rubber with nanoparticles and other ingredients such as the vulcanizing and protective agents were carried out using two roll mixing mill. The formulation used is given in Table 1 . The compositions of the nanoparticle of various biomass and carbon black were $0,5,10,15,20,25,30$ weight $\%$. Note that the zero composition represents the neat or blank rubber as one of the control samples. The compounded composites were moulded and vulcanized using locally fabricated metallic moulds of appropriate test shape and dimensions in order to minimize pre-existing cut in the test samples. The cure conditions for the sulphur vulcanization were $140{ }^{\circ} \mathrm{C}$ for 13 minutes using compression moulding technique in 11 ton hydraulic press.

\subsubsection{Scanning Electron Microscopy (SEM)}

The morphological studies of composites were performed using SEM Phenom world model ProX with acceleration voltage of $15 \mathrm{KV}$. The fractured surface of selected composite samples was coated with a thin lay of gold in order to ensure adequate conduction and prevent surface over charging.

\subsubsection{Thermal study of Composite using Differential Scanning Calorimeter (DSC)}

This study was performed using METTLER TOLEDO STAR SW 13.00 DSC in power compensation mode. In this experiment, $5 \mathrm{mg}$ of selected samples of composites were heated in an aluminum pan from 60 to $400{ }^{\circ} \mathrm{C}$ at controlled heating rate of $10{ }^{\circ} \mathrm{Cmin}^{-1}$ while measuring the corresponding differential heat input to the sample and reference inert material required to keep them at exactly the same temperature.

\subsubsection{Thermo Gravimetrical Analysis (TGA)}

TGA experiments were carried out in air using TGA 4000 by Perkinelmer. In this study, about $40 \mathrm{mg}$ of neat $\mathrm{NR}$ and rubber composites of bamboo (NR-BNC), coconut husk (NR-CHNC), cotton linter (NR-CLNC) and carbon black (NR-CB) were heated from 27-800 ${ }^{\circ} \mathrm{C}$ using heating rate of $10{ }^{\circ} \mathrm{Cmin}^{-1}$. The temperature for different percentages of weight loss, temperature at maximum decomposition and residue at $800{ }^{\circ} \mathrm{C}$ of composites samples were determined.

Table 1: Formulation for the prepared composites

\begin{tabular}{|c|c|c|c|c|c|c|c|}
\hline Sample Code & NR & NC & $\mathrm{ZnO}$ & SA & TMQ & MBTS & Sulpur \\
\hline Neat NR & 100 & 0 & 5 & 2 & 1 & 2 & 3 \\
\hline $\mathrm{NR}-\mathrm{BNC}_{5}$ & 100 & 5 & 5 & 2 & 1 & 2 & 3 \\
\hline $\mathrm{NR}-\mathrm{BNC}_{10}$ & 100 & 10 & 5 & 2 & 1 & 2 & 3 \\
\hline $\mathrm{NR}-\mathrm{BNC}_{15}$ & 100 & 15 & 5 & 2 & 1 & 2 & 3 \\
\hline $\mathrm{NR}-\mathrm{BNC}_{20}$ & 100 & 20 & 5 & 2 & 1 & 2 & 3 \\
\hline $\mathrm{NR}-\mathrm{BNC}_{25}$ & 100 & 25 & 5 & 2 & 1 & 2 & 3 \\
\hline $\mathrm{NR}-\mathrm{BNC}_{30}$ & 100 & 30 & 5 & 2 & 1 & 2 & 3 \\
\hline $\mathrm{NR}-\mathrm{CHNC}_{5}$ & 100 & 5 & 5 & 2 & 1 & 2 & 3 \\
\hline $\mathrm{NR}-\mathrm{CHNC}_{10}$ & 100 & 10 & 5 & 2 & 1 & 2 & 3 \\
\hline $\mathrm{NR}-\mathrm{CHNC}_{15}$ & 100 & 15 & 5 & 2 & 1 & 2 & 3 \\
\hline $\mathrm{NR}-\mathrm{CHNC}_{20}$ & 100 & 20 & 5 & 2 & 1 & 2 & 3 \\
\hline $\mathrm{NR}-\mathrm{CHNC}_{25}$ & 100 & 25 & 5 & 2 & 1 & 2 & 3 \\
\hline $\mathrm{NR}-\mathrm{CHNC}_{30}$ & 100 & 30 & 5 & 2 & 1 & 2 & 3 \\
\hline NR- CLNC $_{5}$ & 100 & 5 & 5 & 2 & 1 & 2 & 3 \\
\hline NR- CLNC $_{10}$ & 100 & 10 & 5 & 2 & 1 & 2 & 3 \\
\hline NR- CLNC $_{15}$ & 100 & 15 & 5 & 2 & 1 & 2 & 3 \\
\hline NR- $\mathrm{CLNC}_{20}$ & 100 & 20 & 5 & 2 & 1 & 2 & 3 \\
\hline NR- CLNC $_{25}$ & 100 & 25 & 5 & 2 & 1 & 2 & 3 \\
\hline $\mathrm{NR}-\mathrm{CLNC}_{30}$ & 100 & 30 & 5 & 2 & 1 & 2 & 3 \\
\hline $\mathrm{NR}-\mathrm{CB}_{5}$ & 100 & 5 & 5 & 2 & 1 & 2 & 3 \\
\hline $\mathrm{NR}-\mathrm{CB}_{10}$ & 100 & 10 & 5 & 2 & 1 & 2 & 3 \\
\hline $\mathrm{NR}-\mathrm{CB}_{15}$ & 100 & 15 & 5 & 2 & 1 & 2 & 3 \\
\hline $\mathrm{NR}-\mathrm{CB}_{20}$ & 100 & 20 & 5 & 2 & 1 & 2 & 3 \\
\hline $\mathrm{NR}-\mathrm{CB}_{25}$ & 100 & 25 & 5 & 2 & 1 & 2 & 3 \\
\hline $\mathrm{NR}-\mathrm{CB}_{30}$ & 100 & 30 & 5 & 2 & 1 & 2 & 3 \\
\hline
\end{tabular}

NR-natural rubber, NC-nanocellulose ZnO-Zinc oxide,S.A-stearic acid, TMQ- trimethylquinolone; MBTSmercaptobenzothiazoledisulfide. 


\subsubsection{Tensile Properties (Tensile Strength, Elongation at Break, Modulus of Elasticity)}

These tests were conducted in accordance to ASTM D412. Tensile tests were carried out at room temperature using universal Instron machine model 3366 with a load cell $1 \mathrm{kN}$. Pre-moulded dumbbell shaped specimens with dimensions of $50 \times 8 \times 4 \mathrm{~mm}^{3}$ were used to perform the experiment at a loading speed of $80 \mathrm{~mm} / \mathrm{min}$. The maximum breaking stress (tensile strength) was calculated using equation 1 :

$$
\sigma_{t}=\frac{F}{b d}
$$

In (1), F is breaking force $(\mathrm{N}), \mathrm{b}$ is the width ( $\mathrm{mm}$ ) of the sample and $d$ is the thickness $(\mathrm{mm})$ of sample. The elongation at break was also calculated using equation 2. Similarly, the modulus of elasticity was calculated using equation 3 .

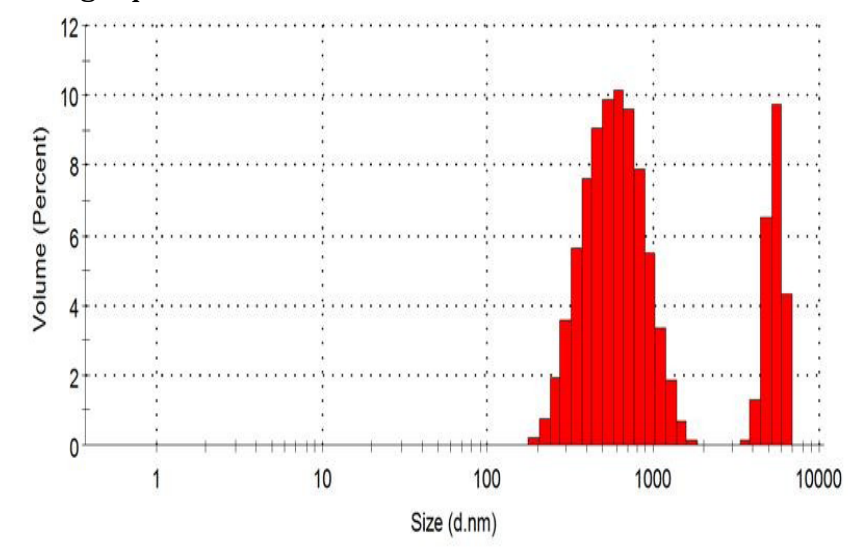

Figure 1 (a): Particle Size of Cotton Linter Based Cellulosic Nanoparticles (Record 4: CLNC av)

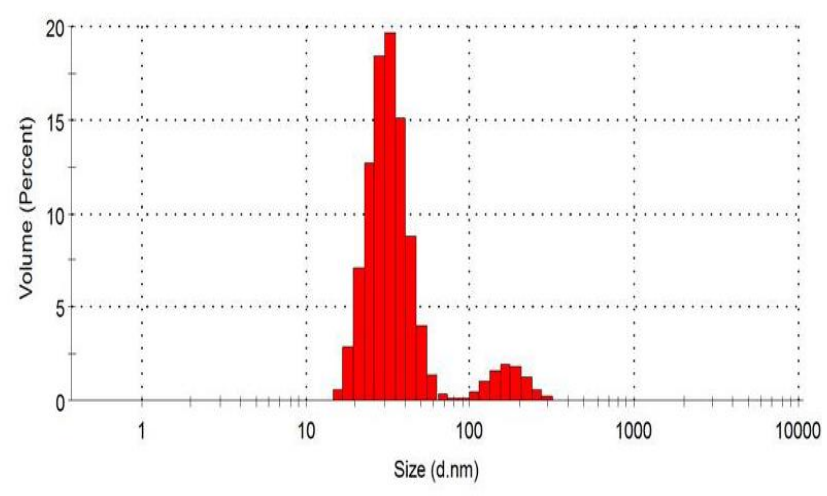

Figure 1 (b) : Particle Size of Bamboo Based Cellulosic Nanoparticles (Record 4: BNC av)

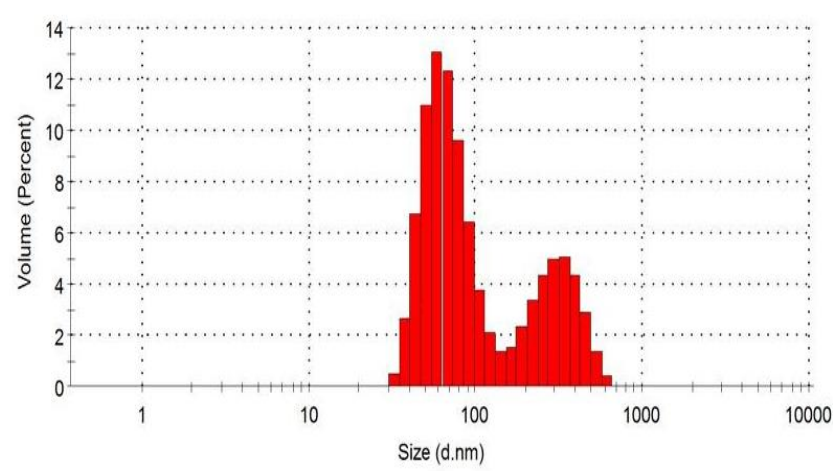

Figure 1 (c): Particle Size of Coconut Husk Based Cellulosic Nanoparticles (Record 4: CHNC av)

$$
\begin{gathered}
\text { Elongation at break }=\frac{\text { Final length at break }- \text { Initial guage length }}{\text { Initial guage length }} \times 100 \%, \\
\text { Modulus of elasticity }=\frac{\text { Maximum stress at break }}{\text { strain at break }}
\end{gathered}
$$

\subsubsection{Flexural Strength of Composites}

A three point flexural test was performed using universal Instron machine model 3366 on pre-moulded rectangular composite samples with dimensions of 100 X $25 \times 8 \mathrm{~mm}$ with a span support of $65 \mathrm{~mm}$. The flexural strength was calculated using equation 4

$$
\sigma_{f}=\frac{3 F L}{2 b d^{2}}
$$

In (4), $\mathrm{L}$ is the span support length ( $\mathrm{mm}), \mathrm{b}$ is width $(\mathrm{mm})$ of test beam, $\mathrm{d}$ is the depth or thickness $(\mathrm{mm})$ of the specimen and $\mathrm{F}$ is the load at a given point on the load deflection curve $(\mathrm{N})$.

\section{RESULTS AND DISCUSSIONS.}

\subsection{Particle Size Distribution}

The results of particle size (see Fig.1) showed that cellulosic particles obtained from bamboo, coconut husk and cotton linters sources were found to be in nanoparticle ranges of 32 to $175 \mathrm{~nm}, 68$ to $311 \mathrm{~nm}$ and 620 to $5408 \mathrm{~nm}$. The exact size of particles is difficult to obtain because of the high number of entanglement and complexity at micro-/nano-structural level.

\subsection{Processing of Composite}

The two roll mixing/compounding of composites were carried out at $70 \pm 5^{\circ} \mathrm{C}$, the highly viscous raw rubber was initially subjected to mechanical shearing under the influence of heavy roll rotating in opposite 


\section{Investigation of Eco-Friendly Cellulosic Nanoparticles Potential as Reinforcement Agent in the Production ... J. O. Oboh, et al}

direction at friction speed ratio of 1.25:1 (i.e back and front roll speed of 275 and $220 \mathrm{rpm}$ respectively) for about 3 minutes to obtain a less viscous and softened mass necessary for rubber-filler dispersion and redistribution. The addition of the nanoparticles were observed to alter the flow pattern of the viscous rubber under the influence of the rotating rolls, this effect became more noticeable as the volume of nanoparticles added were increased. Usually vulcanized rubber composites are considered to be a system where reinforcement particles are embedded in crosslinked rubber matrix. The formation of matrix-nanoparticle network rather than nanoparticle-nanopaticle or matrix-matrix networks is important for effective stress distribution within composite microstructure. Therefore the most important aspect of processing is to achieve reduction of the size of particles aggregation to the ultimate size necessary for the formation of microstructural networks that is essential for reinforcement.

\subsection{Morphological Study of Composite}

Scanning electron microscopy (SEM) probing of composite microstructure gives information about the homogeneity of the composite, presence of voids, micro-scaled dispersion level of the reinforcement phase within the rubber matrix, presence and extent of particle aggregations, sedimentation and possible orientation of the reinforcement phase [2] \& [11]. In addition, the electron imaging allowed the differentiation between rubber matrix, reinforcement phase and other modifying additives most especially zinc oxide $[2,12]$. An investigation of the fractured surface of natural rubber composites reinforced with carbon black and cellulosic nanoparticles obtained from different biomass were carried out using SEM, the resulting images are shown in Fig. 2 (a,b,d \& e).

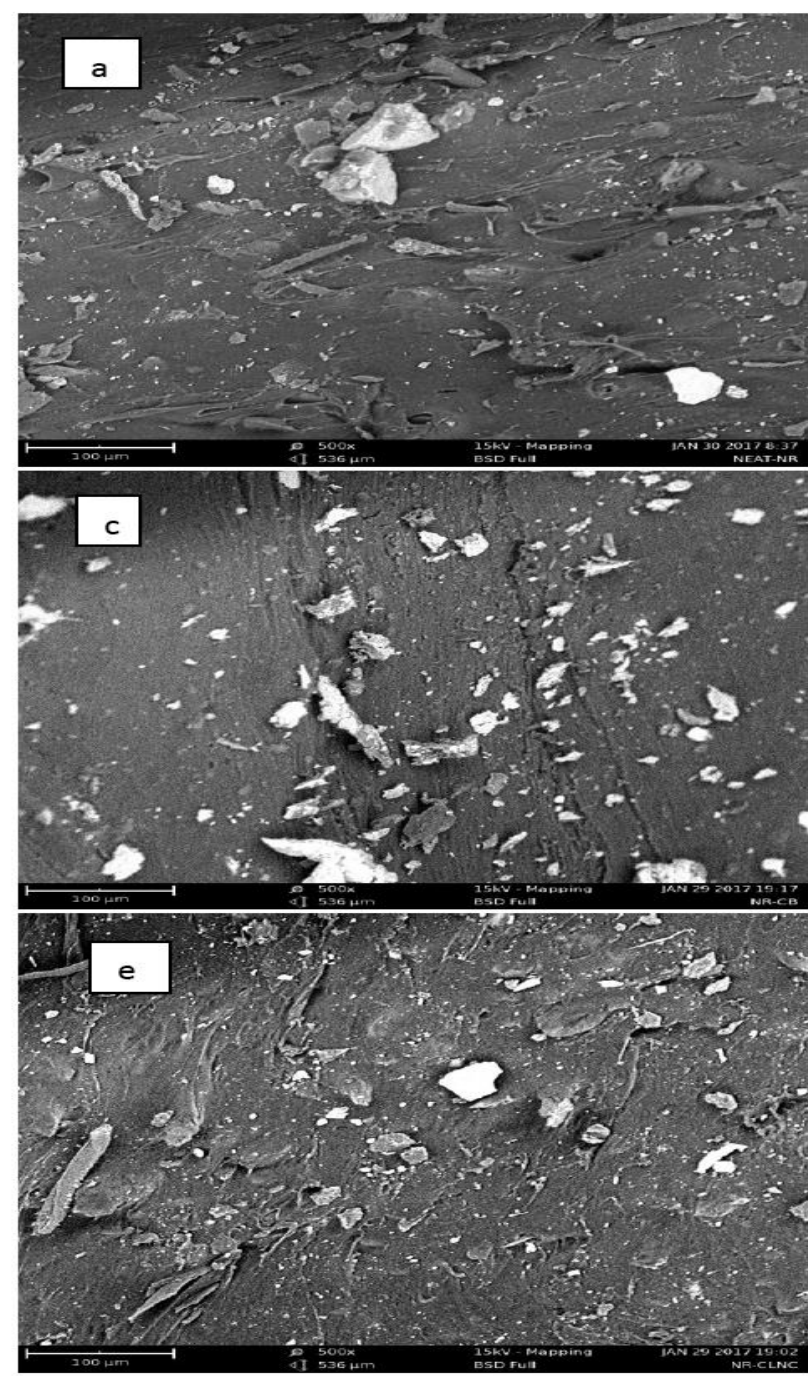

Figure 2: SEM images of NR-Nanoparticles composites at 500x magnification: (a) neat NR (b) NR-BNC (c) NR-CB (d) $N R$-CHNC and (e) NR-CLNC. 
Neat NR as well as the various composites showed the presence of microscaled particles. The white patches seen in the micrographs are attributed to micro-scaled zinc oxide aggregates [2, 12]. The fractured surface of the neat NR (Fig. 2a) was similar to that of the composites containing the different nanoparticles, however the surface of neat NR seems to be more characterized with the presence of voids, cracks or fractured sections and roughness when compared to what is seen in composites containing bamboo and coconut husk based nanoparticles (see Fig. $2 b$ and d). It can be seen that the filled composites have less number of free volume holes (voids or pores) than the neat rubber compound. This can be attributed to even distribution of nanoparticles within the rubber matrix and the possibility of these particles filling up the voids associated with the neat NR. The nanoparticles in the composites prepared using two roll mixing mill are to be randomly oriented and evenly distributed throughout the rubber matrix based on the working principles of the two roll mill. The composite containing cotton linter showed surface topographycharacterized with cracks, voids and cotton linter particle entanglement possibly due to the self woven tendency of cotton fibre, this could suggest a weak interface between the cotton lint particles and rubber matrix.

\subsection{Thermal Properties of Composite}

\subsubsection{Differential Scanning Calorimetry (DSC)}

Differential scanning calorimetry (DSC) is a method of thermal analysis for the investigation of polymer processes that involves a change in heat capacity (second order transformations) or an enthalpy change (first order transformations). In this work, the focus was on the use of DSC to study the fusion and thermal decomposition of vulcanized rubber-nanoparticle based composites. The power compensation DSC mode was used in this experiment, in this mode the rubber composites and an inert reference material were independently heated at a controlled rate of $10{ }^{\circ} \mathrm{Cmin}^{-1}$ in adjacent, separate cells while simultaneously recording their temperature and monitoring the differential heat input to the composite and the reference required to keep both materials at exactly the same temperature. DSC curves for the composite samples are shown in Fig. 3; data from power compensation DSC are plotted as differential energy input (Mw) against temperature $\left({ }^{\circ} \mathrm{C}\right)$.

The negative region of the differential heat input represents an exothermic event such as crystallization while the positive region or value is an endothermic event such as melting.

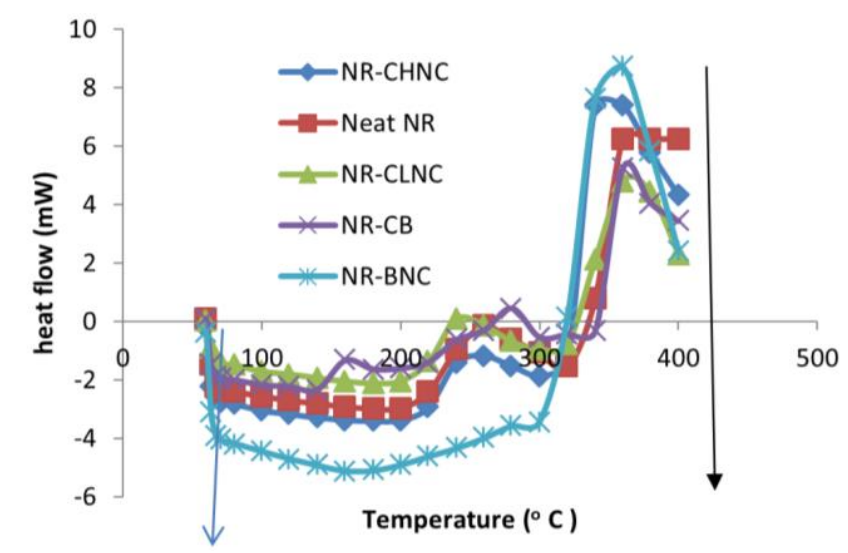

Figure 3: DSC Plots of Neat Rubber, Bamboo, Cotton

Linter, Coconut Husk and Carbon Black based

Composites

Conventionally the first thermal event in the DSC trace or curve is the glass-rubber transition temperature (Tg), above which the polymer chains have mobility and eventually reach a temperature (cold crystallization temperature $\mathrm{T}_{c c}$ ) at which polymer chains are able to organize into crystals, the process of crystallization is exothermic and so differential heat input is negative. On completion of crystallization, a new baseline is established which relates to the specific heat capacity of the polymer samples. As temperature increases further, there is little change until the melting temperature $T_{m}$ is reached, at this point the polymer crystals begin to melt, a process that is endothermic and signified by a positive change in differential heat input [6]. In line with this, Fig. 3 showed two of such DSC trace events as indicated by two arrows on the graph and they correspond to cold crystallization temperature $\mathrm{T}_{\mathrm{cc}}$ and crystalline melting temperature $\mathrm{T}_{\mathrm{m}}$. This two baseline temperatures were found to be basically the same except there was a slight shift in melting temperature of composite reinforced with bamboo particles from $360{ }^{\circ} \mathrm{C}$ to $350{ }^{\circ} \mathrm{C}$. The grass transition temperature ( $\mathrm{Tg}$ ) of rubber compounds usually in the neighbourhood of - 85 to - $75{ }^{\circ} \mathrm{C}$ [2] \& [13], could not be seen in the DSC curves due to the heating range used in this study. The other two peaks as indicated by arrows in the DSC curves for the different composites were in the neighbourhood of 60 and $360{ }^{\circ} \mathrm{C}$ for cold crystallization temperature and crystalline melting temperature respectively. The significant of this is that the presence of nanoparticle reinforcement phase has minimum drift from the 
baseline of the neat rubber matrix and that the composites could be thermally stable up to $360^{\circ} \mathrm{C}$.

\subsubsection{Thermo Gravimetric Analysis (TGA)}

Thermo gravimetric analysis (TGA) determines the thermal degradation behaviour of polymer composites by measuring the change in the weight of the composite sample when heated in air or nitrogen. When rubber compound is heated at lower temperature, moisture and other volatile components will get evaporated first. Further heating of the rubber compound will get part of it degraded and converted into gaseous products with corresponding weight loss which is reflected in TGA curves $[2,13]$. On further heating, all organic matter will be removed leaving behind inorganic components in the compound. The result obtained from the TGA experiment for neat NR and composites reinforced differently with carbon black, bamboo, coconut husk, cotton linter cellulosic nanoparticles are shown Fig. 4. Neat NR and composites of coconut husk (NR-CHNC) showed an initial weight loss of $0.1-0.3 \%$ at about 70 $-100{ }^{\circ} \mathrm{C}$, probably due to loss of moisture during heating.

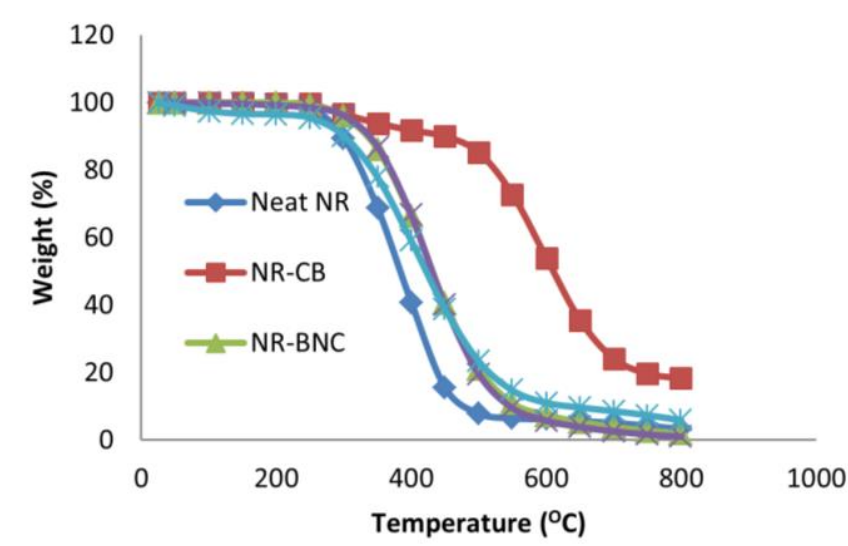

Figure 4: TGA plots of neat NR and rubber composites.

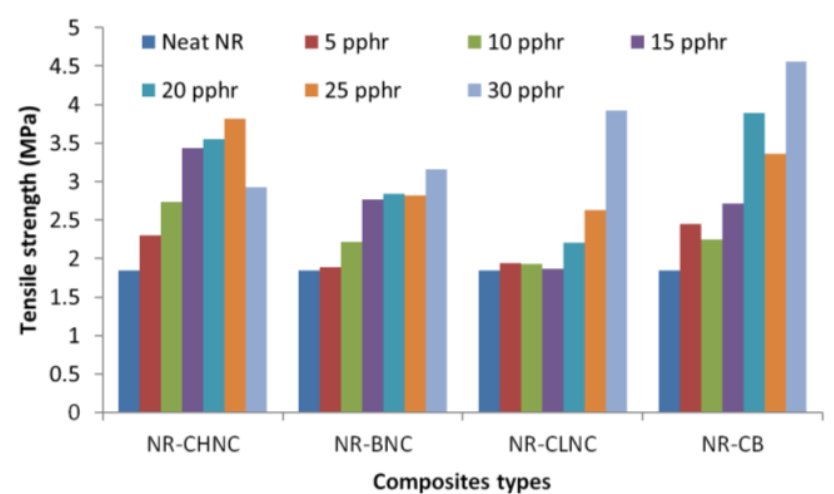

Figure 5: Effect of Filler Type and Loading on Tensile Strength of Composites

The onset of thermal degradation was $266{ }^{\circ} \mathrm{C}$ for the neat rubber and shifted toward 299, 300, 308 and $240^{\circ}$
C upon incorporation of bamboo (BNC), cotton linter (CLNC), carbon black (CB) and coconut husk (CHNC) respectively into the rubber matrix. The reason for this thermal transitional behaviour is attributed to the decreased chain mobility of the rubber matrix in the vicinity of the particles; this might in turn lead to reduction in the rate at which degraded products diffuse from the composite.

\subsection{Tensile Properties \\ 3.5.1 Tensile Strength}

The tensile strength of the composites as presented in Fig. 5, measures the maximum force required to fracture or yield a unit area of the composites under static or quasi-static loading conditions at a defined temperature and strain rate $[7,14]$. The tensile strength of NR-Nanoparticles composites were analysed at room temperature and strain rate of 80 $\mathrm{mm} / \mathrm{min}$. Note that for cross linked rubber, a tear will propagate at lower strains if a pre-existing cut is present in the test sample [6], for this reason the test samples were moulded to the test sample shape and dimensions.

For bamboo nanoparticles based composites (NR$\mathrm{BNC}$ ), the tensile strength was found to increase from 1.8 to $3.16 \mathrm{MPa}$ with increasing BNC content from $0-$ 30 weight \%. Similarly, for cotton linter based composites (NR-CLNC) the tensile strength increased from 1.85 to $3.92 \mathrm{MPa}$ when CLNC content was increase from 0 - 30 pphr while for carbon black(NR$\mathrm{CB})$ composites, the tensile strength increased from 1.85 to $4.5 \mathrm{MPa}$ for $\mathrm{CB}$ content of $0-30$ weight $\%$.Generally, from these data presented the tensile strength increased with increasing weight of cellulosic nanoparticles and carbon black in the rubber matrix, though carbon black gave higher values. This behaviour is manifestation of reinforcement tendencies [15] \& [16] which imply that there was a strengthening effect of these particulate materials due to the role they play by imposing restriction on rubber chains molecular rupture and slippage of these chains past each other. Also the nature of predominated interface (rubberrubber, rubber-particles or particle-particle) formed and the interfacial interaction between the rubber phase and the nanoparticulate materials plays a vital role in the reinforcement of rubber matrix $[4,14,17]$, that is the higher the ability of the rubber to spread round the particle surface during processing (good wettability) the higher the stress require to break the physical bonding between the rubber and the particle hence the higher the tensile strength. Another condition for reinforcement is interfacial bonding and 
adhesion (whether, physical, chemical or both), this determines the stress transfer at the interface $[8,15]$. The tensile strength of coconut husk (NR-CHNC) composites increased from 1.85 to $3.82 \mathrm{MPa}$ increased with increase in CHNC content from $0-25 \mathrm{pphr}$ and declined to $2.93 \mathrm{MPa}$ when the CHNC content was further increased to 30 weight \%., the possible reason for this behaviour is the formation of particle agglomeration (more of particle-particle interface) which can possibly generate point defects within the composite, furthermore stress concentration is likely to occur within the rubber matrix or particle agglomerate with attendant problem of molecular slippage (tendency for a polymer chain to slide past an adjacent chain) within the composite hence decrease in tensile strength will occur. The higher value of tensile strength value of carbon black based composites especially at 30 weight $\%$ can be ascribed to higher surface reactivity of carbon black with polyisoprene molecules as a result of formation of covalent bond when compared with cellulosic particle surface. Previous reports have shown that carbon black is capable of bonding both physically and chemically to rubber phase due to its surface reactivity [4]. The overall maximum level of reinforcements was $166 \%$ for the control sample (NR$\mathrm{CB}$ ) while other samples gave 117, 112 and $76 \%$ for NR-CLNC, NR-CHNC and NR-BNC respectively. Visakh et al.[2] reported $88 \%$ level of reinforcement in the case of natural rubber reinforced nanocellulose obtained from bamboo, this result is very similar to the $76 \%$ recorded for bamboo based composite (NR-BNC) in the course of this study. The high level of reinforcement conferred on rubber matrix by carbon black as in the case of NR-CB was attributed to the Van Der Waal forces of attraction between the carbon black and the rubber, secondly the chemical crosslinks or chemisorptions of the rubber on to the carbon black due to free radical reaction between the carbon atom in the carbon black and in the rubber and lastly the mechanical interlocking of the rubber chains on to the carbon black surface [4].

\subsubsection{Modulus of Elasticity}

The modulus of elasticity is a measure of stiffness of an elastic material or simply the magnitude of the ratio of stress to strain on the point of a material. As can be observed from the results presented in Fig. 6, carbon black based composites (NR-CB) gave a defined trend of increase in modulus of elasticity ( 0.33 to $0.76 \mathrm{MPa}$ ) with increasing volume of the carbon black (0 to 30 weight $\%$.) while other gave an irregular trend.. This increase in modulus of elasticity with increasing carbon

Nigerian Journal of Technology, black content can be attributed to the possible restriction of the rubber molecular chains mobility in the vicinity of the carbon black particles. Conversely, all cellulosic nanoparticles based composites (NR-CHNC, NR-CLNC and NR-BNC) exhibited similar behaviour of irregular trend when their contents were increased from 0 to 30 weight \%.. This behave could be ascribed to the orientation pattern of the particles within the vulcanized rubber matrix

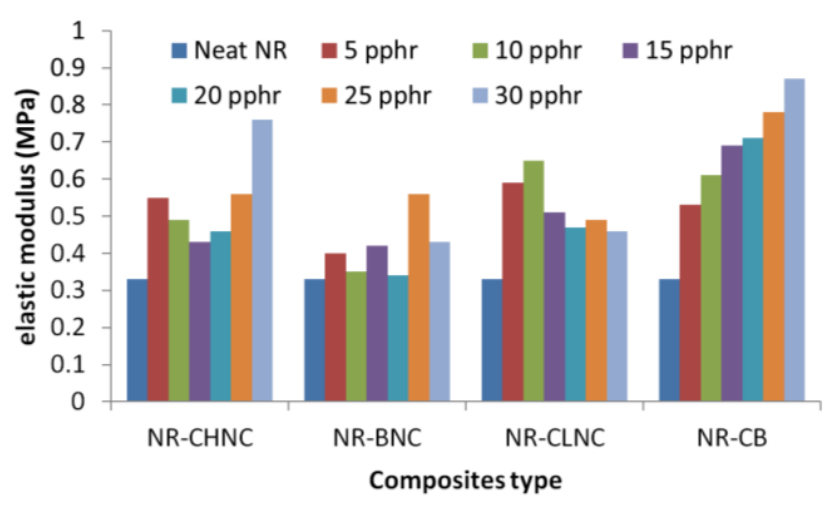

Figure 6: Effect of Filler Type and Loading on Elastic Modulus of Composites

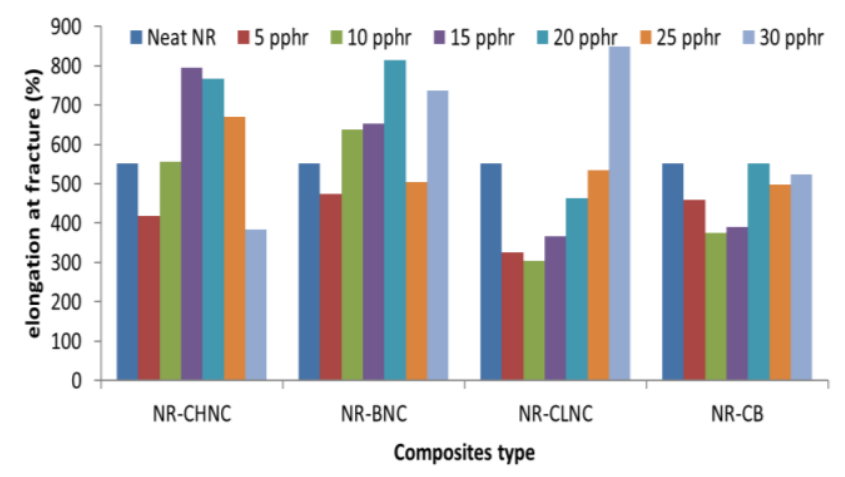

Figure 7: Effect of Filler Type and Loading on Elongation at Break of Composites

\subsubsection{Elongation at Break}

The elongation at break is the strain or percentage increase in the length of the composites when it breaks. The results of the elongation at break are shown in Fig. 7. The percentage elongation at break was observed to have decreased from 552 to $374 \%$ and 552 to $303 \%$ as the cellulosic particles contents were increased from $0-15$ weight \%. for NR-CB and NR-CLNC respectively. Similarly, the percentage elongation at break decreased from 552 to $419 \%$ and 552 to $473 \%$ for NR-CHNC and NR-BNC respectively with increase in particle contents from $0-10$ weight $\%$.

Further increase in volume contents of these particles resulted in an irregular trend. The expected as reported by previous experiments is a decrease in elongation at break with increasing volume of fillers [2], [17], [18] \& [19]. Conversely, in this report elongation at break was found to occasionally increase with increasing volume 
of nanoparticles into the rubber. Gilberto et al. [20] also reported occasional increase in elongation at break with the inclusion of sisal cellulosic nanoparticles on to the rubber matrix. This could be attributed probably to orientation pattern of these particles within the rubber matrix.

\subsection{Flexural Properties}

Fig. 8 shows the effect of nanoparticle type and weight content on the flexural strength (bending strength), of the composites. The flexural strength of neat NR was $0.38 \mathrm{MPa}$.

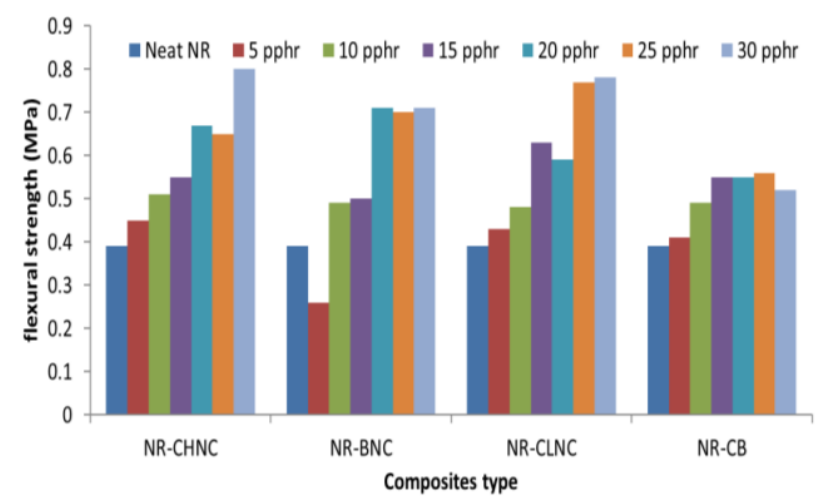

Figure 8: Effect of Filler Type and loading on Flexural Strength.

For all nanoparticle types flexural strength was found to increase with increasing particle weight content from 0 to 30 weight \%., however the flexural strength of composites based on cellulosic particles (NR-BNC, NR-CHNC and NR-CLNC) had higher values of flexural strength compared to carbon black based composites at the same weight content. For instance at $30 \mathrm{pphr}$, NR-BNC, NR-CHNC and NR-CLNC were 0.71, 0.80 and $0.78 \mathrm{MPa}$, respectively. Conventionally, plastic matrix based composites have flexural strength values higher than their corresponding tensile strength values for the same materials while the reverse is the case with rubber matrix based composites because of the inherent flexibility of rubber matrix when compared to plastic matrix. The higher flexural strength of cellulosic particle based composites over their counterpart carbon black based composites as obtained in this experiment can be attributed to the inherent fibrous nature of these cellulosic materials since there is the tendency of this fibrous materials to realign axially in the longitudinal direction of the composite during application of bending (flexure) forcing thereby strengthening the bond between the rubber matrix and the cellulosic material along the same direction [7]. The increase in flexural strength may also be due to the high modulus of the cellulose over that of the rubber matrix.

\section{CONCLUSION}

Natural rubber based composites were prepared in a two roll mill using cellulosic nanoparticles obtained from coconut husk, bamboo and cotton linter as the reinforcing phase in vulcanized natural rubber. Their properties were evaluated and compared with N330 carbon black based rubber composites produced under the same conditions with the cellulosic particles based composites. The morphology studies of the composites showed less numbers of pores or voids especially with composites of bamboo and coconut husk and more micro-scaled aggregation, when compared with the fracture surface of blank or neat rubber. TGA data showed close similarity in the thermal stability of composites reinforced with cellulose particles of all types, and were equally found to be of higher thermal stability when compared with neat rubber. DSC curves of all composites showed similar cold crystallization and crystalline melting temperature peaks of approximately 60 and $360^{\circ} \mathrm{C}$ respectively. The tensile strength values increased with increasing nanoparticles volume fraction, however the highest values of tensile strength obtained were 3.16, 3.82, 3.92 and 4.5 Mpa representing 76, 112, 118 and $150 \%$ reinforcement for bamboo, coconut husk, cotton linter and carbon black based composites respectively. Flexural strength results gave a trend similar to tensile strength. The overall result showed the composites of rubber and cellulosic nanoparticles can be successfully processed in the same way and under the similar conditions as carbon black based composites. Cellulosic nanoparticles obtained from biomass studied in this experiment can replace or serve as alternative materials to carbon black especially in moderate load bearing rubber articles.

\section{REFERENCES}

[1] Jitendra, K. P., Antonio, N.N. and Hitoshi, T. "Fabrication and application of cellulose nanoparticle-based polymer composites". Society of Plastic Engineers, Number 1, pp 770-777, 2012.

[2] Visakh, P. M., Sabu, T., Kristiina, O. and Aji P. M. "Crosslinked natural rubber nanocomposites reinforced with cellulosewhiskers isolated from bamboo waste: Processing and mechanical/thermalproperties", Composites Part a Applied Science and Manufacturing, Number 43, pp 735-743, 2012.

[3] Asore, E. J. Introduction to Rubber Technology. Benin City: Josen Books, 2000. 
[4] Vineetkumar, J. “Carbon black filler reinforcement of elastomers”, Ph.D Thesis, pp 37-49, 2008.

[5] Zhang A, Wang L, Lin Y, and Mi X. "Carbon black filled powdered natural rubber: Preparation, particle size distribution, mechanical properties, and structures", J. Appl. Polym. Sci; Vol. 101, , pp 4933-4939, 2006.

[6] Robert, J. Y. and Peter, A. L Introduction to Polymers. London: CRC Press, Taylor \& Francis group, 2011.

[7] Nassier, A. N. "Studying the effect of nano-carbon black on mechanical properties of unsaturated polyester resin", Iraqi Journal for Mechanical and Material Engineering Vol. 13, number 4, pp 784795, 2013.

[8] Farzana, H., Mehdi, H., Masami, O. and Russell, E. G. "Polymer-matrix nanocomposites processing, manufacturing and application: An overview", Journal of Composites Materials Vol. 40 number 17, pp 1512-1559, 2006.

[9] Martin, A. M. "Introduction of fibre reinforced polymers - polymers and composites: concepts, properties and processing", Intech http:// doi.org 10.5772/54629, 2013.

[10] Thakur, P. Y., Ram, M. Y. and Dinesh, P. S. "Mechanical milling: a top down approach for the synthesis of nanomaterials and nanocomposites", Nanoscience and Nanotechnology, Vol. 2 number 3, , pp 22-48, 2012.

[11] Eldho, A., Merin, S. T., Cijo, J., Pothen, L. A., Shoseyou, 0 . and Thomas, S. "Green nanocomposite of natural rubber/celluloses: Membrane transport, rheological and thermal characteristics", Industrial Crops and Product, Vol. 51, pp 415-424. 2013.

[12] Tunnicliffe, I. B., Thomas, A. G. and Busfield, J. C. "Silica-rubber microstructure visualized in three dimensions by focus ion beam-scanning microscopy", Journal of Microscopy, Vol.246, pp 77-82, 2012.

[13] South, J. T. Mechanical properties and durability of natural rubber. Ph.D Thesis , , pp 34-60, 2001.

[14] William, F. S., and Javad, H. Foundations of Material Science and Engineering. New Delhi, McGraw Hill, 2006.

[15] Fukahori, Y. "Generalized concept of the reinforcement of elastomer: carbon black reinforcement of rubber", Rubber Chem. Technol. Vol. 80, pp 701-710, 2007.

[16] Okoh, B, E., Osabohien, E. and Egbon "The reinforcing potentials of velvet tamarind seed shell as filler in natural rubber compounds", International Journal of Biological and Chemical Sciences. 2014.

[17] Okiemien, F. E., and Imannah, J. E. "Physicomechanical and swelling properties of natural rubber filled with rubber seed shell carbon", Journal of Polymer Materials, Vol.22, number 4, pp 409, 2005.

[18] Oboh, J. O., Agbajelola, D. O. and Okafor, J. O. “ Effect of delignified coir fibre particulate filler on physical properties of natural rubber vulcanizate" International Engineering Conference, FUTMINNA, Nigeria, September 1 - 3, , pp 458 465. 2015.

[19] Aguele, F. G. and Madufor, C. I. "Effect of carbonized coir fibre on physical properties of natural rubber composites", American journal of Polymer Science Vol.2, number 3, pp 28- 34, 2012.

[20] Gilberto, S., Sandra, T., Julien, B., Denilson, D. S. P. and Alain, D. "Mechanical properties of natural rubber nanocomposites reinforced with cellulosic nanoparticles obtained from combined mechanical shearing, enzymatic and acid hydrolysis of sisal fibres", Cellulose, Vol.18, , pp 57-65, 2011. 